\title{
“ESPECIALIZAÇÃO EM ESCOLAR" FORMAÇÃO CONTINUADA DE PROFESSORES DE EDUCAÇÃO FÍSICA NA UNIVERSIDADE FEDERAL DE GOIÁS: UM ESTUDO DE CASO*
}

\author{
Amanda Corrêa Patriarca \\ Graduanda do curso de licenciatura em Educação Física da Faculdade de Educação Física da Universidade Federal de Goiás. \\ Tiago Onofre \\ Professor Licenciado em Educação Física pela Faculdade de Educação Física da Universidade Federal de Goiás.
}

Fernando Mascarenhas

Professor Doutor da Faculdade de Educação Física da Universidade Federal de Goiás.

\begin{abstract}
Resumo: Este estudo aborda a temática da formação continuada em Educação Física, com especial atenção para a pós-graduação lato sensu. Busca compreender algumas das crenças, das demandas e das relações com os saberes que orientam os professores de Educação Física junto à formação continuada. Constitui-se como um estudo de caso do tipo etnográfico, pois se concentrou na dinâmica curricular construída a partir da experiência do curso de especialização em Educação Física Escolar na Faculdade de Educação Física da Universidade Federal de Goiás.

Palavras-chave: educação - educação física - formação de professores.
\end{abstract}

\section{Apresentação}

A s políticas que envolvem a formação de professores em seu conjunto e, especificamente, a formação de professores na área da Educação Física (EF), apontam para significativas mudanças. Isto, pois a reestruturação produtiva e a reforma do Estado, que se expressam pelas transformações no mundo do trabalho e o avanço do neoliberalismo, imputam novas exigências para as políticas educacionais, demandando um projeto de formação alçado aos interesses mais imediatos do mercado. Nesta direção, o re-ordenamento legal que apanha e envolve a formação de professores, principalmente, disposto a partir das novas Diretrizes Curriculares Nacionais, ${ }^{1}$ denota

* Pesquisa apoiada pelo Programa de Bolsas de Iniciação Científica de Licenciatura - PROLICEN-UFG.

1 As novas Diretrizes Curriculares Nacionais relacionadas à área da Educação Física se expressam pelas Resoluções n. 01, 02, 27, 28/CNE e Parecer n. 09/CNE, que trata da formação de professores para a educação básica, e Resolução n. 07/CNE e Parecer n. 158/CNE, que trata da formação profissional específica da Educação Física. um novo perfil de professor, expresso na forma referencial de competências de orientação técnica e instrumental.

Neste cenário, conforme destaca David (2003), é imperativo que a escola busque estabelecer articulações mais imediatas entre o conhecimento, a sociedade e o processo produtivo. Esta necessidade imposta à escola implica na sua responsabilidade pela capacitação de um novo trabalhador. Nesses termos, novas competências são requeridas, também, aos professores. As políticas de formação devem apontar para um novo perfil de professor, dotado de habilidades e competências para melhorar a qualidade de sua intervenção educativa e do ensino escolar, buscando com isso condições necessárias para que possa alterar o quadro de ineficiência e ineficácia por que passa a educação. Diante das demandas do mercado, aos professores são necessárias a atualização, a renovação, a ampliação e a continuidade de sua formação para melhor se enquadrar nesta nova perspectiva.

Ocorre que as novas exigências colocadas para a formação de professores, que se 
impõem pelas reformas educacionais, não se dão somente no plano da formação inicial, mas trazem também desdobramentos para a formação continuada. Sob o argumento da ampliação e permanente re-atualização profissional, seguindo a lógica da empregabilidade, a chamada "reciclagem" acaba por se apresentar como uma obrigação colocada para o professor. Em outras palavras, cabelhes buscar sempre instrumentos para melhor lidarem com os novos problemas, necessidades e desafios de um mercado de trabalho em permanente transformação. Como desdobramento, assistimos a expansão desenfreada do mercado voltado a tal modalidade de formação, seja na forma de cursos de atualização ou de especialização.

Molina Neto (2003) e Alves (2005) assinalam que, no campo específico da formação de professores de EF, esta re-atualização profissional, acontece mediante práticas de formação continuada que se traduzem por cursos de pequena duração, atualizações e atividades de transferência de conhecimentos aplicados. Todavia, apresentando-se como uma opção interessante para o acesso à formação continuada, os cursos de especialização se configuram como alternativa das mais adequadas - diga-se, aligeiradas e flexíveis - para a atualização do professor dentre as possibilidades existentes. Nessa direção, o debate que envolve a problemática da formação de professores convida a uma ampliação de nosso olhar sobre o desafio da formação continuada, em especial, dos professores de EF.

Dentre as possibilidades de investigação acerca do desenvolvimento dos cursos de pósgraduação lato sensu na área de EF, elegemos as crenças e relação com os saberes presentes entre os professores como temática, estudando o caso de um curso de especialização que se organiza a margem do mercado educacional, vinculado a uma instituição federal de ensino superior, mas que não está isolado das determinações históricas atuais, tendo, assim, de dialogar com as expectativas sociais e simbóli- cas geradas a partir da prática docente. Nosso objetivo foi compreender quais são e como se colocam as relações entre os saberes cotidianos dos professores em formação, ${ }^{2}$ bem como compreender as crenças que marcam suas representações sobre a profissão e a intervenção profissional, com os saberes curriculares organizados no processo de formação continuada no curso de especialização em EF escolar da Universidade Federal de Goiás (UFG).

Para a concretização dos propósitos desta investigação, foi realizado um estudo de caso do tipo etnográfico, que envolveu uma pesquisa de campo junto ao curso em questão, sendo utilizada a técnica da observação participante junto às aulas do curso e da entrevista semi-estruturada dirigida aos professores em formação. Seguindo uma lógica espiral, o estudo foi acompanhado de revisão bibliográfica acerca dos estudos que envolvem o tema da formação de professores, o que implicou num constante ir e vir do material de análise aos pressupostos teóricos utilizados que nos serviram para o processo de seleção e classificação dos dados coletados. E lhe foi combinada também a aplicação de questionários sócio-econômicos junto aos professores em formação e uma pesquisa documental que teve como fontes o Projeto Político Pedagógico (PPP) do curso e o portal eletrônico da Faculdade de Educação Física (FEF) da UFG. Em sendo assim, dadas as características de um artigo acadêmico, apresentamos um recorte das reflexões, resultados e conclusões da investigação, com maior atenção para as demandas, a relação com os saberes curriculares e as crenças dos professores em formação a partir da experiência do curso estudado. ${ }^{3}$

2 Valemo-nos da categoria professores em formação para identificar os alunos do curso de especialização em estudo e professores formadores para identificar os professores que atuam como docentes no curso.

3 Para caracterização sócio-econômica do universo dos 20 professores em formação foi aplicado um questionário. Elegeu-se assim uma amostra de 6 professores em formação para a concessão de entrevista semi-estruturada. E foram 


\section{A formação continuada e o caso UFG}

Os cursos de pós-graduação no Brasil surgiram ao longo da década de 1960. Havia uma demanda pela expansão de todo o sistema educacional, acompanhando as mudanças científicas e surgimento de novos campos de saber. Tal dinâmica impulsionou a diversificação das especializações, conduzindo o ensino superior a se organizar em disciplinas especiais voltadas às profissões que clamavam por conhecimento especializado acarretando assim a formação de um professorado competente para atender com qualidade à expansão do ensino superior e preparar o caminho para o decorrente desenvolvimento da pesquisa científica e formação profissional. (OLIVEIRA, 1995; KUENZER, 1998).

Até então a legislação acerca dos cursos de pós-graduação praticamente inexistia. Em 1965, com o Parecer 977 do Conselho Federal de Educação (CFE), é que a pósgraduação foi definida a partir da modalidade stricto sensu, referente aos cursos de mestrado e doutorado, e da modalidade lato sensu, referente aos cursos de especialização e aperfeiçoamento. De acordo com este mesmo parecer, a primeira modalidade era voltada para a formação de pesquisadores, professores e profissionais de alto nível. E a segunda, voltada para a formação para o mercado de trabalho (OLIVEIRA, 1995). Em 1976, o CFE demonstrava preocupação com a expansão e baixa qualidade desses cursos, mas é somente a partir das resoluções do já Conselho Nacional de Educação (CNE), antigo CFE - Reso-

realizadas 20 sessões de observação junto a 2 das 6 disciplinas do curso. Já o documento básico de pesquisa foi o PPP do curso, referente à Resolução n 483 da Câmara Ensino, Pesquisa e Extensão (CEPEC) da UFG, que regulamenta o curso de Especialização em Educação Física Escolar, bem como do PPP do curso de licenciatura, referente à Resolução n ${ }^{\circ} 715$ da CEPEC, que fixa o currículo do curso de graduação em EF - Licenciatura Plena. Destaca-se ainda que todos os envolvidos na pesquisa, coordenador do curso, professores formadores e professores em formação participaram da investigação com livre e esclarecido consentimento. lução CNE/CES no 01/2001, que estabelece as normas para o funcionamento de cursos de pós-graduação; e Resolução CNE/CES no 01/2007, que estabelece normas para o funcionamento de cursos de pós-graduação lato sensu, em nível de especialização -, que um marco regulatório mínimo é fixado. Todavia, segundo Gomes (1999), a formação continuada na modalidade da especialização ainda é vista pelo mercado como "terra de ninguém", devido á falta de regulamentação quanto à sua avaliação e rigorosidade.

Não por acaso, segundo dados do Instituto Nacional de Estudos e Pesquisas Educacionais Anísio Teixeira (INEP), atualmente existem 8.866 cursos de especialização no Brasil. A Região Sudeste concentra o maior número de cursos, 4.955 (55,9\%). Chama atenção que as regiões Centro-Oeste e Nordeste totalizam mais de 1.200 desses cursos em funcionamento, número superior aos 951 registrados na Região Sul. O grande número de cursos de especialização no Brasil é fruto da sua desenfreada expansão e oferta por meio das Instituições de Ensino Superior (IES) privadas, que resguardadas pela falta de uma regulamentação mais rígida, ofertam $7.939(89,5 \%)$ do total destes cursos. Entre as públicas, nas municipais estão 412 (4,6\%), nas estaduais, 269 (3\%), e nas federais, 246 $(2,8 \%)$. Em relação à organização acadêmica, a grande maioria dos 8.866 cursos de especialização existentes no país está em faculdades: 7.567 (85,3\%). Já as universidades concentram $920(10,4 \%)$ do total de cursos e os centros universitários $379(4,3 \%){ }^{4}$

No caso da FEF da UFG, o primeiro curso de especialização foi criado em 1997, na área de EF escolar. Segundo o PPP do curso, tal iniciativa se fundou na proposição do corpo docente desta IES de elaborar um curso de pós-graduação lato sensu com perfil

4 Dados constantes do Informativo INEP, ano 5, n. 145, 2007. Disponível em: http://www.inep.gov.br/informativo/ informativo145.htm. Acesso em 04 dez. 2007. 
crítico e também no encaminhamento resultante do I Seminário de Avaliação da Educação Física em Goiânia, realizado em abril de 1996, quando pouco mais de 700 professores vinculados à Rede Municipal de Ensino de Goiânia e à Rede Estadual de Ensino de Goiás reivindicou da UFG a criação de um curso de especialização vinculado aos problemas ligados ao ensino da EF na escola. Com a implementação do curso de especialização em EF escolar, além de articular a formação inicial na modalidade de licenciatura à formação continuada, a FEF buscava responder efetivamente à demanda dos professores por atualização e aprofundamento no campo das teorias, da reflexão crítica e da qualificação das ações educacionais no âmbito da EF escolar. Assim, em termos gerais, procuramos avaliar em que medida o curso de especialização em EF escolar da UFG vem, de fato, conseguido materializar seus objetivos, ${ }^{5}$ estabelecendo diálogo com as necessidades e interesses destes professores, consequentemente, com seus saberes, demandas e práticas.

5 Sendo o currículo da formação inicial de viés sócio-crítico, conforme se verifica no PPP do curso de licenciatura em EF daUFG, há um o continuum com a formação continuada. O curso de especialização em EF escolar, dentre outros objetivos visa "melhorar a qualidade do ensino da Educação Física na rede pública de ensino, [...] intervir no processo de capacitação e formação continuada de professores da rede pública, atualizando os conhecimentos na área de EF \& Esportes e realimentando o próprio curso de licenciatura da FEF face ao desenvolvimento de pesquisa e da intervenção social" (UFG, 2002, p. 5). Reafirma assim o objetivo do curso de licenciatura que é o de "formar um tipo de intelectual público que deve lidar com a corporalidade humana em seu sentido concreto e sensível, técnico e estético, com o objetivo de promover transformações nos comportamentos, nos valores políticos e morais das novas gerações para garantir a paz e o desenvolvimento de valores humanos com ética no país" (UFG, 2004, p. 15); além de "formar professores com capacidade para atuarem nas diferentes manifestações e expressões culturais do movimento humano, com ênfase na produção de conhecimento e fomento da intervenção acadêmico-profissional no sistema educacional básico, no esporte educacional e nas práticas educativas de saúde e lazer social que interagem historicamente e no cotidiano com a escola, cultura e a sociedade" (UFG, 2004, p. 20).
Para a análise, estabelecemos inicialmente como categorias investigativas o saber docente e as experiências sócio-culturais. O saber docente, definido por Tardif (2002, p.36), pode ser entendido como "um saber plural, formado pelo amálgama, mais ou menos coerente de saberes oriundos da formação profissional e de saberes disciplinares, curriculares e experienciais". Além de identificarmos quais são os saberes docentes, levamos em consideração as experiências dos professores em formação. Tardif (2002) e Figueiredo (2004) argumentam que as experiências sócio-culturais agem como uma espécie de "filtro", influenciando escolhas, mediando interações, estabelecendo hierarquizações e selecionando o conhecimento acadêmico na dinâmica curricular. No que se tange à EF, Figueiredo (2004, p. 91) equipara essas experiências "às vivencias proporcionadas pelas interações que ocorrem nas relações sociais que incluem atividades e experiências corporais e valores a ela atribuídos".

Assim, conhecer as experiências dos professores em formação significa, ao mesmo tempo, conhecer também seus saberes experienciais ou saberes cotidianos que, para Tardif (2002, p. 39):

\begin{abstract}
São os saberes desenvolvidos pelos próprios professores no exercício de sua função e na prática de sua profissão, baseados no seu trabalho cotidiano, brotam da experiência e são por ela validados. Incorporam-se à experiência individual e coletiva sob a forma de habitus e habilidades, de saber-fazer e de saber-ser.
\end{abstract}

Além dos saberes experienciais ou saberes cotidianos, buscamos conhecer ainda os saberes curriculares organizados a partir do PPP e experiência do curso. Segundo Tardif (2002, p.38), esses saberes:

Correspondem aos discursos, objetivos, conteúdos e métodos a partir dos quais a instituição escolar [neste caso, a FEF da UFG] categoriza e apresenta os saberes sociais por ela definidos e selecionados como modelos da cultura erudita e de formação para a cultura erudita [...] apresentam-se na forma de programas [...] que os professores devem aprender a aplicar. 
Estamos partindo do pressuposto de que a relação entre os saberes cotidianos e os saberes curriculares no processo de formação inicial, na área da $\mathrm{EF}$, é uma relação tensa, é o que se pode constatar na formação inicial a partir do curso de licenciatura em EF da UFG, conforme nos aponta Ávila (2005). Mas ao ingressarem no curso de "especialização em escolar", será que os professores em formação, de posse de suas expectativas forjadas ao longo de sua trajetória profissional antes de ingressar no curso, rejeitam e se frustram ante uma relação de tensão com os saberes curriculares organizados? Para aprofundarmos nossa análise em torno da questão, cabe conhecer quais as crenças presentes entre eles. Os $s a-$ beres experienciais ou saberes cotidianos se incorporam ao acervo cultural dos professores em formação como formas de saber-ser e de saber-fazer, ou seja, como crenças acerca da sua atividade docente. No conceito de Molina Neto (2003, p. 150), tais crenças podem ser entendidas como:

Um tipo de conhecimento impregnado de emoções, preconceitos e valores que o professor [neste caso, o professor em formação] constrói - resultado das informações que acessa e das relações que estabelece com seu contexto mais amplo.

$\mathrm{Na}$ mesma direção, além das crenças que se fazem presentes no processo de formação continuada, nos deparamos com as demandas destes professores em formação. Esperam extrair dos saberes curriculares os conteúdos e a forma que atendam aos interesses mais imediatos da sua prática pedagógica, algo que contribui para uma hierarquização dos conhecimentos estabelecida por eles no processo de formação, selecionando os saberes disciplinares que julgam mais adequados e que correspondem aos seus interesses. Figueiredo (2004, p. 106) afirma que "muitos dos alunos em formação atuam como professores de EF em diversos espaços (formal e não formal) de trabalho e, por isso, esperam extrair das disciplinas os conteúdos e a forma que atendam aos seus interesses", o mesmo vale dizer para os professores em formação. Este "filtro" usado para selecionarem os conteúdos que mais lhe interessam é fruto de sua relação com os conteúdos selecionados e organizados pelo curso, acaba dando origem a um curriculo oculto, "onde figuram as aprendizagens regulares produzidas pelo curso e que não consta nos planejamentos" (SANCHOTENE; MOLINA NETO, 2006, p. 272).

A compreensão da relação dos saberes cotidianos, das crenças e das demandas e interesses dos professores em formação com os saberes curriculares é para nós absolutamente relevante. Isto, pois ao conhecer a cultura de formação dos professores em formação do curso de especialização em EF escolar da UFG, estaremos de posse de uma possível "ferramenta" político-pedagógica para que se possa intervir e dialogar com algumas concepções incorporadas e transferidas pelos professores em formação para o curso de formação continuada e vice-versa.

\section{Os professores em formação}

Com a aplicação de questionários, recolhemos dados que permitem caracterizar o perfil do professor em formação que se encontra no curso de especialização em EF escolar na UFG. Dos 30 professores em formação que ingressaram no curso, 20 continuavam freqüentando por ocasião da pesquisa de campo ${ }^{6}$, dos quais 18 foram respondentes. Destes, 9 (50\%) são homens e $9(50 \%)$ são mulheres. A turma tem a média de idade de 29 anos. Do total, $11(61,2 \%)$ se formou no curso de licenciatura em EF da própria UFG, 6 (33,3\%) no curso de licenciatura em EF da unidade de Goiânia da Universidade Estadual de Goiás (ESEFFEGO-UEG) e $1(5,5 \%)$ no curso de licen-

6 A pesquisa de campo foi desenvolvida ao longo do $2^{\circ}$ semestre de 2007. O curso havia começado no $1^{\circ}$ semestre do mesmo ano e tinha sua conclusão para o $1^{\circ}$ semestre de 2008, com a realização dos trabalhos monográficos. 
ciatura em EF do campus de Goiânia da Universidade Paulista (UNIP). Em sua maioria, com exceção de um formado em 1978, todos os demais professores em formação concluíram a formação inicial 2002 e 2006 , sendo que 5 ( $27,7 \%)$ já estavam fazendo o seu segundo curso em nível de pós-graduação lato sensu na modalidade de especialização. Todos estavam empregados, estando $14(77,7 \%)$ trabalhando em escolas - dos quais $12(66,6 \%)$ em escolas públicas e $2(11,1 \%)$ em escolas particulares -, $3(16,6 \%)$ trabalhando em academias de ginástica e $2(11,1 \%)$ em outros locais de trabalho, como clubes, condomínios, clínicas etc.

Para aprofundarmos nossa análise, foi definida uma amostra representativa do grupo que envolveu 6 alunos selecionados para a realização de entrevistas semi-estruturadas, a partir das quais pudemos identificar as demandas que orientam seus interesses pela formação continuada, a relação que estabelecem com os saberes curriculares, bem como as crenças que forjaram a partir de sua formação inicial e a partir do seu trabalho docente.

\section{Demandas e interesses}

Para compreender as demandas que orientam a formação continuada, num primeiro momento, buscamos saber das motivações dos professores em formação ao buscarem o curso de especialização em EF escolar da UFG.

Justamente para me ajudar no dia-a-dia da escola. Para me ajudar a acalmar um pouco as angustias, os conflitos com os quais a gente se depara frente a escola. Porque, quando eu saí da faculdade, eu tinha muitos planos, muitos anseios frente à atuação na escola. E aí quando a gente se depara com a realidade escolar, agente fica meio perdido. (Professora em formação 1).

Percebe-se o anseio por mais e novos conhecimentos para melhor lidarem com a realidade escolar. A inexperiência e a incerteza quanto ao seu papel forçam os professores a buscarem uma melhor qualificação, tendo em vista que a realidade escolar é quase sempre uma realidade precária em termos de estrutura e das condições de trabalho.

A formação continuada se apresenta como uma forma de melhorar e aprofundar as discussões acerca da educação.

O meu curso não tratou de maneira especifica as questões da educação. Vi muito superficialmente a área especifica da educação. E eu senti que tinha que buscar... E eu já tinha vindo da escola como técnico desportivo e eu senti a necessidade de buscar mais conhecimento, até pra base de concurso mesmo, porque com os conhecimentos da graduação eu jamais conseguiria chegar numa escola pública (Professor em formação 3).

Devido à dificuldade que tive com a ligação da
teoria e da prática, mesmo não estando na es-
cola no momento. O meu interesse é dar aula
na escola, na prefeitura, e então já estou me
preparando. (Professora em formação 2).

Ao buscarem aprofundar estudos nos temas da educação que avaliam terem sido tratados superficialmente na formação inicial, visam também ampliarem suas possibilidades de ingresso no serviço público, o que nos leva a perceber que as pressões do mundo do trabalho - isto é, a empregabilidade - são contingenciais entre os professores em formação. Os saberes disciplinares são vistos, portanto, como saberes instrumentais para concursos públicos e não propriamente para a qualificação de sua prática pedagógica. A opção pela escola enquanto campo de intervenção profissional por parte dos professores em formação é justificada em função das vantagens que o serviço público oferece. Direitos como assistência médica, férias, $13^{\circ}$ salário, previdência social e estabilidade são apontados como atrativo. Mesmo com todos os seus problemas, a escola apresenta vantagens quando comparada a incerteza e precariedade imposta pela flexibilidade dos contratos de trabalho em outros campos.

Em outros casos, a especialização é vista como um curso preparatório de acesso ao mestrado. 
Primeiro eu quis fazer especialização na UEG, conclui agora... para contribuir com meu projeto de mestrado (Professor em formação 2).

$\mathrm{Eu}$ acho que eu ainda não estou preparada para enfrentar um mestrado, por bagagem teórica. E aí eu acho que a especialização pode estar me preparando para o mestrado (Professora em formação 1).

De todo modo, seja no sentido de qualificar sua prática pedagógica, ingressar no serviço público, acessar o mestrado ou para aprofundar os conhecimentos tratados na formação inicial, o curso de especialização para esses professores, é apontado como de extrema validade para sua vida profissional.

Frente ao campo profissional está sendo de grande valia. Está sendo extremamente interessante, frente ao conhecimento, as possibilidades de estudo, as possibilidades de leitura, as possibilidades de convívio com outras pessoas (Professora em formação 1).

Para outros, mesmo não atuando profissionalmente diretamente no campo escolar, o curso não tem um sentido diretamente prático. Porém, além de ampliar sua visão acerca da EF, o curso tem oportunizado a melhor compreensão do papel docente.

Profissionalmente ainda não teve muita influência, pois na academia não conseguimos colocar em prática estes conhecimentos, porém, na vida pessoal, me fez entender melhor o papel do professor (Professora em formação 1).

Para os egressos da licenciatura de outras IES, a ampliação dos conhecimentos acerca da EF, bem como a acessibilidade econômica, são pontos destacados ao reconhecerem um diferencial no curso de especialização da UFG.

É o perfil mesmo, a questão dos professores, da gente conhecer a história da faculdade, como que é movida. A questão do preço também ajuda, porque mesmo sendo paga ${ }^{7}$ ela é

7 Não há cobrança de mensalidades no curso de especialização em EF escolar da UFG, porém é cobrada uma taxa muito acessível. A questão de que quem vem pra cá, já vem consciente de que vem para estudar (Professor em formação 1)

Mas o chamado diferencial do curso em relação a outros cursos é apontado, principalmente, em função do perfil de formação de viés sócio-crítico identificado.

O curso está muito voltado para a formação do aluno no sentido crítico, porque esse aluno que hoje está na FEF... A intenção é que ele possa ir pra escola pública e que ele tenha consciência do seu papel político dentro da escola, que é a essência da graduação aqui. A própria linguagem dos professores, onde eles colocam que a intenção da FEF é visar a escola pública e a formação do professor que vai pra escola pública, por isso a finalidade do curso é formar um professor pautado na consciência crítica, que entenda as relações do mundo e a sua função dentro da escola (Professor em formação 3).

É o de criar ambiente para discussão da prática e buscar teorias que auxiliem e melhorem o trabalho do professor na escola em busca de uma escola mais democrática que forme alunos mais críticos (Professora em formação 2).

Neste sentido, o curso não só vem ampliando os conhecimentos, as leituras acerca da escola, da educação e da EF. Busca socializar novas ferramentas para o trato pedagógico dos conteúdos próprios à $\mathrm{EF}$, além de problematizar a realidade escolar, com todos os seus problemas e as possibilidades de superação.

O curso tem servido para melhorar a minha prática na escola... novas possibilidades de estar trabalhando certos conteúdos que eu tinha dificuldades. O curso está mostrando que as dificuldades que eu enfrento na escola, de as vezes não saber trabalhar, de não ser respeitada, de não ter muita abertura na escola, esse curso está mostrando que não é um problema

de matrícula correspondente ao valor de 3 parcelas de $\mathrm{R} \$$ 200,00. Conforme discrimina a resolução referente ao PPP do curso, o montante arrecadado é aplicado na própria manutenção e melhoria das condições estruturais do curso, além de pagamento de passagens e diárias de professores convidados, externos ao quadro profissional da UFG. 
só meu, isso é um problema do sistema, um problema da EF. O curso está sendo muito interessante, pois tem me ajudado a melhorar minha atuação na escola, na maneira de falar, no planejamento e no trato com o aluno e está me mostrando que não estou sozinha nas varias dificuldades (Professora em formação 1).

Como a maioria dos professores em formação já atua em ambiente escolar, a troca de experiências, de situações vividas no cotidiano escolar ganha grande importância dentro do curso, no sentido de ampliarem as discussões com os autores e com a realidade escolar. Todavia, a despeito das contribuições que o curso vem trazendo aos professores em formação, muitos problemas são identificados, em especial, referentes à sobreposição de conteúdos tratados na formação inicial.

Embora as aulas tenham sido bem repetitivas da graduação, uma segunda forma de ver, reler e discutir nos leva a pensar de forma diferente e ir um pouco além. Porém estava esperando que fosse mais além do que a graduação (Professora em formação 2).

Muitas vezes eu vejo meus colegas colocando que eles queriam que o curso fosse além, principalmente os colegas aqui da FEF, porque o curso está voltando muito para o que eles já tinham visto. Mas eles não têm idéia de como está sendo importante para quem não veio daqui. No curso eu consegui recuperar o que teve na graduação de novo e a partir daí ampliar, primeiro porque forma um grupo mais homogêneo, o grupo consegue levantar uma discussão de modo mais equilibrado, sem que alguns apenas consigam entender o que está sendo discutido e outros não. E pra mim, hoje, eu estou diferente do que eu era quando eu entrei aqui no sentido profissional mesmo. Eu tenho uma visão mais ampla da EF e vou conseguir desenvolver um trabalho diferenciado (Professor em formação 3).

Percebemos claramente um conflito de expectativas e avaliação, sendo que os professores em formação egressos da UFG esperam mais do curso. Já os egressos de outras IES demonstram um estranhamento receptivo frente aos conteúdos tratados no curso. Além deste problema, os professores em formação apontam limites relacionados à relação entre teoria e prática.

Acho que falta a construção da práxis pedagógica pelos próprios professores. Não ficar geralmente só na exposição teórica (Professor em formação 2).

Nós tivemos pouquíssimas vivências, assim...
não vou dizer aula prática. Eu acho que eu
melhoraria o planejamento, da escrituração do
cronograma da seqüência de módulos, eu acho
que falta isso, melhoraria a questão de certas
programações de certos conteúdos. Melhora-
ria o planejamento, com a maior possibilidade
de vivência, de aula prática talvez (Professora
em formaçẫo 1).

Além de chamarem atenção para a ausência de vivências no curso, são feitas também algumas sugestões para a qualificação do curso, com apontamentos que envolvem grande número de críticas à organização do trabalho pedagógico.

\section{Relação com os saberes curriculares}

Em relação às disciplinas do curso, muitos professores em formação indicam aquelas pelas quais têm mais preferência, construindo assim uma hierarquização dos saberes disciplinares em função de sua articulação ou não com as demandas postas pela prática pedagógica na escola.

Eu não estou na escola, então aproveitar elas num sentido prático, eu não estou aproveitando nenhuma delas. Algumas estão respondendo meu objetivo de eu ter vindo pro curso, que foi ampliar o meu conhecimento do que é EF e qual o seu sentido para a escola (Professor em formação 3).

Algumas disciplinas ligadas ao esporte figuram dentre aquelas bem avaliadas, tanto pela receptividade dos professores em formação aos conteúdos esportivos, mas também em função do tratamento pedagógico que os professores formadores conferiram aos saberes disciplinares. 
$\mathrm{Na}$ disciplina metodologia e ensino da cultura corporal desportiva, o professor conseguiu diretamente trabalhar os problemas que nós temos dentro da escola. (Professor em formação 1).

Pedagogia do esporte tive um aproveitamento bom por essa disciplina estar ajudando a acalmar as inquietações e ver que há novas possibilidades de atuação da EF na escola. Foram professores bem comprometidos que souberam conduzir muito bem o conteúdo. São professores que têm um conhecimento do que é a escola, da realidade da escola, porque os outros professores trabalharam o conteúdo muito por fora, muito aéreo, sem muita contribuição palpável para a escola, para nossas inquietações, paras as nossas dificuldades. [Eles fazem agente ler, fazem agente estudar, e isso é bom, porque de uma forma ou de outra ele tem que ler, ele tem que estudar, tem que pegar alguma coisa e fazer para estar melhorando, porque os outros professores da forma como trataram o conteúdo, foi muito abstrato (Professora em formação 1).

Os saberes disciplinares reconhecidos como válidos e relevantes se destacam, sobretudo, quando proporcionam a reflexão e a compreensão acerca da escola e da própria prática pedagógica da EF. Por outro lado, percebe-se uma rejeição aos saberes disciplinares na medida em que estes não estabelecem diálogo com o contexto escolar. Além disso, a sobreposição de conteúdos da formação continuada em relação à formação inicial é também avaliada negativamente.

EF e aprendizagem sócio cultural... por enquanto, porque está no começo... coisa de filogênese, ontogênese... não gosto desse tipo de aprendizagem não. Eu me vejo muito na aula de psicologia que eu não gostei na época que eu fazia a graduação. É muita falação do conteúdo em si. Por enquanto não está dando muito para chegar lá onde a gente está: na escola (Professora em formação 3).

A disciplina de didática e de dança foi praticamente uma cópia da graduação, sendo lidos os mesmos textos, feitos os mesmos trabalhos e as mesmas aulas (Professora em formação 2).
Apesar dos limites e tensões apontados pelos professores em formação em relação aos saberes das disciplinas, todos os entrevistados afirmaram que o curso tem qualificado sua intervenção na escola, o que vem não só a confirmar certo êxito do curso quanto aos seus objetivos, mas que denota também correspondência às suas expectativas.

Juntando a bagagem da graduação somando a ela a bagagem da pós-graduação, isso reflete na minha atuação na escola, na questão da fala, do planejamento, de construção e consolidação de certos projetos, porque na minha escola a EF nunca teve um professor e aí, os professores que estão a mais tempo na escola, eles ficam meio surpresos com certas falas e certas colocações. (Professora em formaçãa 1).

Primeiro, me fez verificar a questão do currículo, a importância do PPP, a importância de você ter uma estratégia pedagógica para se trabalhar com os alunos, ter um direcionamento dos conteúdos (Professor em formação 2).

O curso, na verdade, até me fez despertar para escola. Quando eu vim buscar o curso eu não tinha muito interesse em ir pra escola. Eu vim buscar para ampliar a minha visão e meus conhecimentos acerca da EF na escola, para que se um dia eu viesse para a escola, ele pudesse servir como base para a minha atuação docente. A partir das aulas eu percebi a importância de eu estar na escola, porque não adianta você estar fora do problema questionando. Nesse sentido eu acho que o curso contribuiu. Hoje eu compreendo melhor o que é a escola, compreendo como pode ser minha atuação dentro da escola, da proposição política, da formação de valores. Espero sim poder atuar e contribuir nesse sentido (Professor em formação 3).

A importância do curso, bem como a relevância e validade dos saberes disciplinares, ou seja, dos saberes curriculares é reconheci$\mathrm{da}$, portanto, quando os professores em formação se sentem instrumentalizados quanto aos desafios mais imediatos colocados pelo fazer pedagógico inerente ao processo de ensinoaprendizagem da EF na escola. 


\section{As crenças acerca da EF}

Essa ênfase no saber da experiência, algo que se reflete no processo de formação continuada na busca dos professores em formação pela ampliação das vivências e pela apropriação de saberes que possam qualificar a intervenção, também se evidencia quando analisamos suas crenças acerca do papel da EF dentro da escola.

O papel da EF na escola é de ajudar a enfrentar os problemas pela qual a escola passa, de tentar junto com o coletivo solucionar os problemas pela qual a escola tem passado. E na quanto aos alunos, eu acho que o papel da $\mathrm{EF}$ é de possibilitar novas vivências corporais, novas vivências de pensamento. (Professora em formação 1)

Além das crenças acerca do papel da EF na escola, buscamos identificar as crenças sobre o professor de EF, por exemplo, sobre seu reconhecimento e valorização dentro da escola.

Vai depender qual o referencial da escola, quais os objetivos que a escola quer, se a escola for tradicional, voltada para o mundo com valores neoliberais, a EF pode contribuir de uma forma bem substancial, que é a questão do esporte de alto rendimento. A idéia de se querer fazer esporte de alto rendimento dentro da escola, que são as competições, de se fazer só por fazer, isso vai depender do coletivo, de como esse professor se posiciona lá dentro (Professor em formação 1)

Fica evidente que o reconhecimento e a valorização do professor de EF está também relacionado ao projeto e perfil da escola. Se o professor de EF se aproxima deste perfil, ele é valorizado. Para outros professores em formação, o professor de EF é o próprio culpado pela falta de reconhecimento ao seu trabalho por não demonstrar compromisso com a escola, com a mudança, ou seja, ele mesmo se desvaloriza.

Em boa parte das escolas o professor se mostra competente. Com interesse e com uma formação mais crítica consegue espaço para discutir os problemas da escola e mudar regras e coisas estruturais da escola. Apenas o professor que tem consciência, que está em busca de conhecimento, que reivindica e luta, mostra seus saberes, suas vivências e seus valores, sendo realmente valorizado (Professora em formação1).

A desvalorização do professor de EF é também associada ao desconhecimento do objeto de estudo da EF, ao limitado conhecimento sobre o seu papel e a função da escola. $\mathrm{E}$ isso se reflete na sua imagem junto à comunidade escolar.

Fora da escola ele não é valorizado pelos outros profissionais da saúde e dentro da escola também ele não é valorizado pelos profissionais da educação. Não é valorizado porque não sabe muito bem o que ele tem que tratar dentro da escola (Professor em formação 3).

Identificamos também as crenças acerca do trabalho do professor de EF, não reconhecido como trabalho intelectual. A falta de estudos e de compromisso frente à realidade escolar caracteriza o que os professores em formação pensam do professor de EF.

\begin{abstract}
Se formos analisar se foram os professores que não tiveram, mesmo os mais antigos, não tiveram formação continuada, que não estudam diariamente, que não tem pelo menos a curiosidade de ler pelo menos as revistas que chegam na escola, eles não são intelectuais, eles são reprodutores, eles são práticos, porque estão acomodados com o que eles aprenderam na graduação (Professora em formação 1).
\end{abstract}

A avaliação é feita com referência ao seu desinteresse pela leitura, pelo estudo, pela ampliação do seu conhecimento, independente da perspectiva de trabalho e intervenção pedagógica que o professor de $\mathrm{EF}$ tenha. O trabalho intelectual cobraria do professor de EF a ampliação de seu acervo de conhecimentos, na sua visão de mundo e na compreensão sobre o objeto de seu trabalho. 
Acho que na área de educação, não só o professor de EF, mas todos têm que ser intelectuais, tem que ficar dias e dias lendo, não ficando só na área da EF, mas ficar lendo outros conhecimentos, outras perspectivas do dia-a-dia. $\mathrm{O}$ professor tem que ser intelectual, se não, cai no fazer pelo fazer, não há aula produtiva, não aguça o conhecimento do aluno (Professor em formação 2).

Ao identificarmos as crenças acerca da valorização do professor e sua identidade intelectual, acabamos por caracterizar quem é o "bom" professor de EF segundo os professores em formação.

O bom professor é aquele que entende o papel da escola com possibilidade de transformação da sociedade, que domina conhecimentos que são necessários para sua inserção nas discussões, que entende que a escola necessita de um novo modelo de currículo, que não seja reduzido apenas em grade de disciplinas. Tem de pensar na vivência e em conhecimentos que serão necessários à vida do aluno cidadão, consciente e crítico (Professora em formação 2).

É aquele que não deixa o fazer pelo fazer, que cumpre também o papel de construção do conhecimento junto com os alunos, que trabalha com projetos de intervenção da realidade, que pesquisa, que faz um plano de aula. O bom professor de EF tem que fazer um projeto direcionado e tentar conquistar a comunidade escolar para esse fazer pedagógico (Professor em formação 2).

Há ainda o entendimento de que os professores em geral, não só o de EF, vêm sofrendo com a crescente desvalorização do seu trabalho, o que é determinado, sobretudo pela precarização da educação e da escola, com destaque para a falta de materiais, para os baixos salários, o que vem a refletir na sua prática, desgastando sua vontade e seu entusiasmo frente ao ensino, comprometendo seu compromisso. De todo modo, as crenças forjadas a partir da prática e experiência profissional dos professores em formação, em especial aquelas relacionadas ao "mau" professor, influenciam a "filtragem" dos saberes das disciplinas. Mas a identificação destes professores com os saberes curriculares seguem uma hierarquização que, a despeito de suas crenças acerca do "bom" professor de EF, confere maior importância aos saberes curriculares que garantem a vivência e a relação direta com sua prática pedagógica na escola.

\section{Considerações finais}

Este trabalho buscou compreender quais são e como se colocam as relações entre os saberes cotidianos, orientados pelas crenças, experiências e demandas dos professores em formação, com os saberes curriculares no processo de formação continuada em EF na UFG. Através do diálogo e análise de conteúdos das entrevistas podemos perceber que os professores em formação "filtram" os saberes e conhecimentos organizados pelo curso em função da relação com a sua prática pedagógica, no sentido de melhor qualificar a sua intervenção na escola. No entanto, percebe-se, a partir as crenças destes professores em relação ao papel da EF na escola e ao trabalho do professor de $\mathrm{EF}$, uma clara preocupação com a qualificação de seu trabalho no sentido da mudança da realidade escolar, algo que reflete a influência da experiência da formação inicial, em grande parte, vivida pelos professores em formação na própria UFG.

O curso de especialização em EF Escolar, ao estabelecer um continuum em relação ao curso de licenciatura em EF, prioriza o aprofundamento dos conteúdos tratados na formação inicial, com grandes limites no que se refere ao diálogo com a realidade escolar experimentada pelos professores em formação. $\mathrm{E}$ isto é algo que se dificulta ainda mais, segundo eles, pelos problemas referentes à organização do trabalho pedagógico interna ao curso. Todavia, avaliam que o curso tem, em alguma medida, respondido às suas expectativas, no sentido de melhor qualificá-los para a sua atuação na escola, ampliando a sua compreensão e visão acerca da sociedade, do mun- 
do, da escola e da própria EF. Mas chamam atenção tais expectativas, pois se relacionam ainda à possibilidade de ascensão na carreira, na busca por melhores salários e preparação para o ingresso no magistério público.

Enfim, concluímos que o curso de especialização em EF escolar vem logrando significativo êxito quanto aos seus objetivos e demandas dos professores em formação. Ainda que eles não sejam plenamente atendidos em suas expectativas de uma relação mais direta do curso com a prática e com o cotidiano escolar, reconhecem o "diferencial" da "especialização em escolar" da UFG ante o concorrido mercado educacional que se criou em torno da pós-graduação lato sensu na cidade de Goiânia e no país, qual seja, sua orientação pedagógica e política por uma qualidade socialmente referenciada.

Graduate studies in school physical education: in-service ongoing teacher education program for pe teachers at universidade federal de goiás: a case study

Abstract: This study addresses the issue of ongoing education programas in Physical Education, with special attention to graduate programs. It aims at understanding some of the beliefs, demands, and relations established with the other fields of knowledge that guide $\mathrm{PE}$ teachers in their ongoing education programs. This ethnographic case study focused on the program dynamics built from the experience of the graduate course in School Physical Education created by the Department of Physical Education at Universidade Federal de Goiás.

Keywords: Education - Physical Education - Teacher Education Programs

"Experiencia en la escuela" educación continua para profesores de educación física en la universidad federal de goias: un estudio de caso

Resumen: Este estudio plantea la cuestión de la educación continua en la Educación Física, con especial atención a postgraduados en general. Busca comprender algunas de las creencias, de las demandas y de las relaciones con el conocimiento que guían a los profesores de Educación Física de la formación continua. Es como un estudio de caso de tipo etnográfico, pues se centró en planes de estudio dinámico construido a partir de la experiencia del curso de especialización en la Escuela de
Educación Física en la Facultad de Educación Física, Universidad Federal de Goiás

Palabras-clave: Educación - Educación Física - Formación de profesores

\section{Referências}

ALVES, Wanderson Ferreira. Os professores e sua formação: uma análise nos cursos de especialização em Educação Física Escolar, In: Congresso Brasileiro de Ciências do Esporte, 15.; Congresso Internacional de Ciências do Esporte, 1, Porto Alegre, Anais... Porto Alegre, 2005.

AVILA, Regiane. A relação entre os saberes cotidianos e os saberes curriculares no processo de formação inicial em educação física. Trabalho de conclusão de curso. (Licenciatura em Educação Física) - Faculdade de Educação Física, Universidade Federal de Goiás, Goiânia, 2005.

DAVID, Nivaldo Antonio Nogueira. Novos ordenamentos legais e a formação de professores de educação física: pressupostos de uma nova pedagogia de resultados. Dissertação. (Mestrado em Educação Física) - Faculdade de Educação Física, Universidade Estadual de Campinas, Campinas, 2003.

FIGUEIREDO, Zenólia Campos. Formação docente em educação física: experiências sociais e relação com o saber. Movimento, Porto Alegre, v. 10, n. 1, p.89-11, jan./abr. 2004.

GOMES, Cândido Alberto. Pós-Graduação lato sensu: terra de ninguém? Infocapes, Brasília, v. 7, n. 2, 1999.

KUENZER, Acacia Zeneida. A formação de educadores no contexto das mudanças no mundo do trabalho: novos desafios para as faculdades de educação. Educação e Sociedade, São Paulo, vol. 19, n. 63, p. 105-125, 1998.

MOLINA NETO, Vicente. Crenças do professorado de educação física das escolas públicas de Porto Alegre - RS/Brasil. Movimento, 
Porto Alegre, v. 9, n.1, p.145-169, janeiro/ abril de 2003.

OLIVEIRA, Fátima Bayma de. Pós-graduação: educação e mercado de trabalho. Campinas: Papirus, 1995.

TARDIF, Maurice. Saberes docentes e formação profissional. Petrópolis: Vozes, 2002

UNIVERSIDADE FEDERAL DE GOIÁS, FACULDADE DE EDUCAÇÂO FİSICA. Projeto do curso de especialização em educação física escolar. Goiânia: FEF/UFG, 2002.

Projeto politico-pedagógico do curso de licenciatura em educação física. Goiânia: FEF/ UFG, 2004.

URROZ SANCHOTENE, Mônica; MOLINA NETO, Vicente. Habitus profissional, currículo oculto e cultura docente: perspectivas para a análise da prática pedagógica dos professores de educação física. Pensar a Práti$c a$, v. 9, n. 2, Goiânia, 2006.

Recebido em: 05/12/2008

Revisado em: 08/12/2008

Aprovado em: 16/12/2008

Endereço para correspondência

mandinhacp@hotmail.com.

tiagoonofre007@hotmail.com.

fernando.masca@uol.com.br. 